\title{
Cost-effectiveness in glaucoma. Concepts, results and current perspective
}

\author{
Custo-efetividade no glaucoma. \\ Conceitos, resultados e perspectiva atual
}

Ricardo Augusto Paletta Guedes ${ }^{1,2,3}$, Vanessa Maria Paletta Guedes², ${ }^{2}$, Alfredo Chaoubah

\begin{abstract}
Glaucoma is the leading cause of irreversible blindness in Brazil. Its prevalence and incidence tend to increase significantly in the future, mainly due to the population increase and aging. The scarcity of health care resources and the increasing costs in health require a balanced analysis of health interventions and an efficient allocation of resources. The cost-effectiveness and cost-utility studies are important because they allow a comparison between different alternatives in terms of both their costs and their results. For this purpose, mathematical modeling (such as Markov modeling) is commonly used as the analytical method. The literature, including in Brazil, has plenty of evidence of cost-effectiveness and cost-utility in glaucoma. This article aims to review in a practical way the concepts of economic evaluation in health, describe the different types of health economic studies, as well as the results of cost-effectiveness and cost-utility studies in glaucoma in the literature.
\end{abstract}

Keywords: Glaucoma/diagnosis; Glauco/therapy; Glaucoma/economics; Public Health; Health economics; Cost-benefit analysis

\section{ResUMO}

O glaucoma é a principal causa de cegueira irreversível no Brasil. Sua prevalência e incidência tendem a aumentar significativamente no futuro, principalmente devido ao aumento da população e ao seu envelhecimento. A escassez de recursos para a saúde associada ao aumento da disponibilidade e dos custos das tecnologias em saúde exige uma análise parametrizada destas tecnologias e uma alocação eficiente dos recursos. Os estudos de custo-efetividade e custo-utilidade são importantes, pois permitem uma comparação entre diferentes alternativas tanto em termos de seus custos quanto de seus resultados. Para isto, modelos matemáticos (como modelagem de Markov) são comumente utilizados como método de análise. Existem na literatura muitas evidências de custoefetividade e custo-utilidade no glaucoma, inclusive no Brasil. Este artigo se propõe a revisar de maneira prática os conceitos de avaliação econômica em saúde, os tipos de estudos econômicos em saúde, bem como os resultados dos estudos de custo-efetividade e custo-utilidade na área de glaucoma na literatura.

Descritores: Glaucoma/diagnóstico; Glaucoma/terapia; Glaucoma/economia; Saúde Pública, Economia da Saúde; Análise de custo-benefício

\footnotetext{
${ }^{1}$ Universidade Federal de Juiz de Fora, Juiz de Fora, MG, Brazil.

${ }^{2}$ Santa Casa de Misericórdia de Juiz de Fora, Juiz de Fora, MG, Brazil.

${ }^{3}$ Centro Oftalmológico Paletta Guedes, Juiz de Fora, MG, Brazil.

The authors declare nop conflicts of interests.
}

Received for publication em 04/09/2015 - Accepted for publication 10/11/2015 


\section{INTRODUCTION}

$\mathbf{U}$ nderstanding the cost of a certain condition is crucial to the economic planning of efforts aimed at reducing the burden of this condition. ${ }^{1}$ Several countries have already explored and characterized the cost of visual impairment and blindness. ${ }^{2-4}$

An increased prevalence of glaucoma is expected in the next years as the population and life expectancy grow. ${ }^{5-6}$ Thus, its economic impact is significantly increased. Knowledge of the cost of using resources and standards of treatment of glaucoma patients are important condition to assess the impact of this increase in prevalence in resources for health.

As glaucoma is a disease of genetic origin, its primary prevention is still impracticable and the only way to prevent blindness is through early diagnosis and effective treatment. Often the diagnosis is made with advanced disease, where the necessary resources for treatment and control are generally more costly. In General, a cost increase is observed with increased severity of the disease; that is, the more advanced the disease, the more is spent with it. ${ }^{7}$

The ageing of the world population, along with increased costs in health and resource scarcity, requires a cost-effective allocation of resources in the treatment and control of glaucoma. ${ }^{8}$ There is evidence that the costs decrease and the quality of life improves with early diagnosis and treatment in glaucoma. ${ }^{8} \mathrm{~A}$ cost-effective analyses has already been used in glaucoma for different goals.

The aim of this study is to have an updated and practical review of the concepts and of the more recent studies involving a cost-effective analysis, a specific type of economic study on health for glaucoma.

\section{Studies of economic evaluation in health}

The availability of new forms of treatment and diagnosis requires knowing how to better allocate resources. According to Vianna and Caetano (2001), the health technology assessments (HTA) have become important for a number of reasons: great variability of clinical practice, uncertainty about the true impact of certain diagnostic or therapeutic interventions, speed of development and dissemination of new technologies, and incompatibility between new technologies and the ones already established. ${ }^{9}$

The health economic evaluations are part of the HTA, where both the costs and the consequences of health technologies, like drugs, devices and medical equipment; medical procedures, behaviors, and models of health care, are assessed in a parameterized way. There are different types of studies proposing an economic evaluation in health. They are an attempt to assist in decision making by health managers, but also to support the clinical practice guidelines. ${ }^{9-13}$

The components of a health economic evaluation are as follows: alternatives under study (usually a technology or practice already in general use, and another or others that will be tested and compared in relation to the previous one); the costs and consequences of each alternative. ${ }^{9-13}$

The main types of economic evaluation differ as to the outcome measure used for the study of the consequences of the alternatives under study. They are: cost-minimization; costeffectiveness; cost-utility and cost-benefit. ${ }^{9-13}$

Whenever the alternatives have the same outcome (final result) and in the same magnitude, it makes no sense to compare the outcome. In such cases, a cost-minimization study is more indicated. In this type of study, the costs of each alternative are collected and compared. The cheaper alternative in this case is the best from an economic point of view. ${ }^{9-13}$

Both the costs and the consequences of the alternatives are assessed in the cost-effectiveness studies, because the outcomes of these alternatives are the same, but in different magnitudes. In this type of study, the effectiveness is measured in natural units (for example: ratio of patients reaching the target intraocular pressure (IOP), or ability to reduce IOP in $\mathrm{mmHg}$ ). The results are usually expressed by the incremental costeffectiveness ratio (ICER), which shows how much is a unit of added benefit with the alternative under study. The ICER calculation is made by an equation in which the result shows the ratio between the difference in costs of the alternatives (alternative A cost - alternative B cost) in the numerator, and the difference in the effectiveness (alternative A effectiveness - alternative B effectiveness) in the denominator. ${ }^{9-13}$

Four results are possible in the cost-effectiveness assessments: the alternative studied is more expensive and more effective; it is more expensive and less effective; it is cheaper and more effective, and it is cheaper and less effective. When the alternative to be assessed is more expensive and less effective, we say that it was "dominated" by the other alternatives under study, and in theory it should be rejected. The alternative is called "dominant" when it is cheaper and more effective at the same time, and theoretically should be adopted. ${ }^{10-12}$

The doubt is usually present when the alternative is more expensive and more effective, or cheaper and less effective. Should these alternatives be adopted or rejected? To answer that, we use the value of ICER corresponding to the cost of each benefit achieved with each alternate (for example: $\mathrm{R} \$ \mathrm{mmHg}$ of IOP reduction). There is a theoretical limit under which administrators or the society would be willing to pay to reach a particular health benefit. This limit is called the threshold for cost-effectiveness. In the USA, this threshold is usually considered as $\$ 50,000 /$ benefit achieved. ${ }^{12}$ The World Health Organization (WHO) suggests a value of up to 3 times the value of the GDP (Gross Domestic Product) per capita in the country. In Brazil this amount would be approximately $\mathrm{R} \$ 81,000.00 /$ benefit. ${ }^{14}$

Therefore, an intervention is considered cost-effective if it is the "dominant" alternative (more effective and cheaper at the same time), or if it is more expensive and more effective, but with costs per benefit not exceeding the threshold of cost-effectiveness.

Cost-effectiveness studies should only be used in cases where the outcome measure has a great clinical significance and is a terminal event of the alternatives under study. Otherwise, there is the risk of difficulty in interpreting and generalizing the results. Due to this difficulty in finding good clinical outcome parameters for many pathologies, a metric capable of capturing an important outcome and with clinical significance for any pathology was considered.

All diseases have an impact on the quality of life or the amount of life, or on both. A measure simultaneously encompassing the concept of maximizing the quality and quantity of life of patients was developed from the concept of patient preference (utility values). These measures are: Quality-adjusted life years (QALY) or disability-adjusted life years (DALY). ${ }^{9-13,15-16}$

When the outcome measure in studies of economic evaluation is QALY or DALY, the study is named cost-utility study. Some consider this type of study as a subtype of the costeffectiveness study. Anyway, it is the most indicated one, because 
it allows the results to be compared among different pathologies, because the outcome studied (quality and quantity of life) is the same. The reasoning for the studies of cost-utility is the same as for the cost-effectiveness studies. Depending on the case, the costeffectiveness ratio or the incremental cost-utility ratio (ICUR) is applied, and the choice of the most cost-effective alternatives (here the term cost-effective alternative is kept, even though it is a costutility study) follows the same principles of "dominance" and cost-

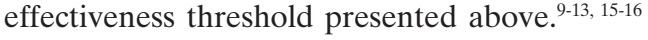

Finally, in cost-benefit studies, both costs and benefits are measured and expressed in monetary values. There are ways to monetize the benefits in health, but they are open to criticism and enhancements. The results of this type of assessment can be expressed by the incremental cost-effectiveness ratio (the same reasoning of ICER), or by calculating the net benefit, which is the difference between the monetary values earned with each alternative and costs (for example: Net benefit $=[\mathrm{R} \$$ alternative 1 Benefit - $\mathrm{R} \$$ alternative 0 Benefit] - [R $\$$ alternative 1 cost - R $\$$ alternative 0 cost] $){ }^{10}$

Other less common economic evaluation studies are as follows: cost-consequence studies and disease cost studies. The cost-effect studies try to make an inventory of all the costs and all the results related to an intervention in health, but data is presented in a disaggregated way, and there is no calculation of the ICER. The cost of illness studies try to identify all costs involved in a specific disease (prevention, diagnosis, treatment and rehabilitation costs). These studies may be related to the prevalence of the disease (costs in a given period of the disease) or the incidence of the disease (costs throughout the life of the new cases of the disease). ${ }^{10}$

An important part in any health economic study is the definition of the types of costs to be studied. There are different types of costs, which are: direct costs (medical and non-medical), indirect costs and intangible costs. Direct medical costs include fees, hospital costs, medicines, equipment, procedures, etc., and direct non-medical costs are those related to transportation, caregiver, rehabilitation, etc. On the other hand, the indirect costs are linked to the loss of productivity of the patient and/or caregiver. Intangible costs (pain, suffering, etc.) are difficult to measure, and are usually excluded from the analysis. When the analysis uses both direct and indirect costs, it is said that it is assessing the cost from the perspective of the society. ${ }^{9-12}$

The health economic evaluation studies increasingly use methods based on decision analysis in their methodology. These methods will be presented below.

\section{Decision analysis on economic evaluation in health}

The decision analysis is the application of an analytical method (model) to compare systematically different decision options. It graphically demonstrates the options, and facilitates the calculation of values required to compare them. In the area of health economics, it helps in the selection of the best alternative or more cost-effective one. ${ }^{11}$

It is important to remember that the quality of the results of a decision analysis is closely linked to the information used to build the model. Decision makers shall assess critically the structure of the model, as well as the probabilities, cost estimates and the assumptions used. ${ }^{11}$

The most used types of economic modeling in health studies are: decision trees, Markov modeling and simulation of discrete events. ${ }^{17}$

The decision trees are simpler models involving short-term consequences on health interventions, such as prevention or treatment of acute infections, for example. They can also be used for some chronic diseases that can be cured (for example, for a surgical treatment). The major limitation of the decision tree is that it does not incorporate time in building the model. ${ }^{11-12}$

In cases involving chronic or complex diseases presenting changes in the health condition over a period of time, the models of state transition or the Markov model should be the chosen. ${ }^{11-}$ ${ }^{12}$ These models enable researchers to identify changes in quality of life, the quantity of life, and the cost of the disease or intervention in a time period when different options of health interventions are studied. The periods of time between the different health condition are called cycles. ${ }^{11-12}$ The probabilities of transition between different health states can be kept constant over time (Markov chain analysis), or may differ depending on the cycle (Markov process analysis). ${ }^{11}$ The limitation of Markov modeling is to assume that the probability of moving from one state to another does not depend on medical conditions that the patient might have experienced before, which may not be a realistic representation for some researches. More advanced analysis, such as discrete event simulation, have been used to overcome this limitation. ${ }^{11-12}$

The discrete event simulation models are used when the health condition changes discreetly over time, and therefore are more flexible than Markov modeling. These models represent complex processes and situations due to the events that may occur and may represent different clinical situations, such as: exacerbation of a process, pathological decompensation or a new clinical situation. ${ }^{17}$

Outcome measures for economic evaluation in glaucoma

The outcome measures can be different in the study of glaucoma. Measures such as capacity of pressure reduction are the most commonly used in clinical studies, but they have little value for economic evaluation studies.

For cost-effectiveness studies, some outcome measures that could be considered in the economic evaluation would be: reduction of intraocular pressure $(\mathrm{mmHg}$ or percentage in relation to the baseline measure); proportion of stable patients during treatment; ratio of patients who reached the target IOP (e.g. $<18 \mathrm{mmHg}$ ); ratio of blindness at the end of the follow-up period; etc.

However, as noted, the amount of possible outcomes to be analyzed in a single disease like glaucoma is huge. Hence the need to use an outcome measure, such as QALY (derived metric of utility values), which takes into account the quality of life affected by glaucoma, but still allowing the comparison with different harms to health. ${ }^{15}$

The utility values were developed in the late 1940s based on the utilitarian philosophy, and have been used in the literature to measure the quality of life associated to a given health condition. ${ }^{11-12,15-16}$ By convention, a utility value equal to 1.0 is related to a perfect health condition, while a utility value of 0.0 is related to death. ${ }^{9-13,15-16,18}$ Utility values enable the objective quantification of the improvement in the quality of life afforded by an intervention, and lead to the composition of QALY. A QALY corresponds to a year lived in perfect health. ${ }^{10-12}$

There are mainly 4 ways to obtain the utility values: time trade off (TTO), standard gamble (SG, willingness to pay (WTP) and multi-attributes (utility values obtained indirectly from generic research instruments like the EuroQol-5 D). ${ }^{19}$

The TTO, the most used method, first asks the person to answer how much remaining life (in years) they imagine they 
will still have. Then they must answer how many of these remaining years they believe they have they would be willing to trade (lose) for perfect health until they die. This ratio (remaining years / imaginary life expectancy) is then subtracted from 1.0 to give the utility value. ${ }^{19}$

In $\mathrm{SG}$, the respondent is asked which is the highest percentage of immediate death risk they would be willing to take for a treatment to bring them perfect health for the rest of their lives. This percentage value is subtracted from 1.0 to give the corresponding utility value. ${ }^{19}$

The utilities obtained by the WTP method are calculated from the percentage of a certain amount of monetary value (salary, savings, etc.) that the person would be willing to pay to be cured from a disease. This percentage value is subtracted from 1.0 to give the corresponding utility value. ${ }^{19}$

The Brazilian Ministry of health, by its Guidelines for Economic Evaluation, suggests the use of the TTO method to obtain the utility values for the Brazilian population. ${ }^{16}$

Utility measures have many advantageous features to evaluate the quality of life. They are: they cover several dimensions of the individual as a whole; sensitive to small changes in health condition; reliable and reproducible; applicability to all health areas; short time to be applied; easily understood by the respondents; good internal validity; can be used for studies of health economics. ${ }^{20}$

In ophthalmology, as the vision decreases in the better eye of a given patient, there is a decrease in the utility values. ${ }^{21-22}$ Patients with bilateral amaurosis (absence of light perception in both eyes) have an average utility value of 0.26 , whereas patients with perception of light in one eye have an average value of $0.47 .{ }^{21}$ It is known that the utility values have a good reproducibility over an extended period of time; they don't seem to suffer the influence of systemic comorbidities (diabetes, heart disease, cancer, stroke and/or kidney failure); and they have a good correlation to the visual acuity in the better eye. ${ }^{18,21-24}$ Utility values have already been obtained in the literature for patients with diseases of the retina, cataract and glaucoma. ${ }^{21-22,25-27}$

In Brazil, Paletta Guedes et al. obtained utility values with two methods (SG and TTO) for patients with primary openangle glaucoma. They noted that the utility values were inversely proportional to the visual function in the better eye, whether measured with visual acuity or the Mean Deviation (MD) index of automated perimetry (visual field). The utility values by the TTO to the Brazilian population ranged from 0.84 for visual acuity better than $20 / 40$ to 0.71 for visual acuity worse than 20 / 200. When considering the visual function depending on the degree of commitment of the visual field in the better eye, the utility values (TTO) ranged from 0.86 (MD better than -6.00 $\mathrm{dB})$ to 0.75 (MD worse than $-12.00 \mathrm{~dB}){ }^{22}$

The same authors also evaluated if the type of treatment (surgical or clinical) of glaucoma would influence the utility values for this population. The results of this study showed that the type of treatment, whether clinical, surgical or laser, has no impact on the utility values. ${ }^{28}$

\section{Cost-effectiveness and Cost-Utility in Glaucoma} Screening and Treatment of Ocular Hypertension

Burr et al. studied if the population screening for glaucoma would be cost-effective. Their findings showed that the screening of the general population was not cost-effective due to the high cost and low prevalence in the general population. However, screening groups considered of high risk for glaucoma could be cost-effective. ${ }^{29}$
In evaluating a patient with suspected glaucoma, the study of risk factors is crucial to decide who should be treated. According to Doshi and Singh, from the economic point of view, it would be more cost-effective to treat only those patients at high and moderate risk of developing glaucoma. ${ }^{8}$ Medeiros and colleagues developed a risk calculator based on the work of Ocular Hypertensive Treatment Study (OHTS) able to estimate the risk of developing glaucoma in 5 years according to the age, IOP, central corneal thickness, aspect of the optic nerve, Pattern Standard Deviation (PSD) index of the computerized campimetry, and presence of Diabetes mellitus. ${ }^{30}$ Kymes et al. used the Markov model to discover that the treatment of ocular hypertension with a high risk of developing glaucoma (IOP $>24 \mathrm{mmHg}$ and risk of progression $>2 \%$ ) was cost-effective from the individual point of view, when measured in QALYs. ${ }^{31}$ They considered that the treatment of all ocular hypertension was not cost-efetivo. ${ }^{31}$ The same result was found by Stewart et al..$^{32}$ These authors suggest selecting and treating only patients at high risk of conversion, for example: old age, high IOP, and low corneal thickness, and increased excavation of the optic nerve. ${ }^{32}$

\section{Primary Narrow-Angle Glaucoma (PNG)}

Only one study in the literature has evaluated the costeffectiveness relation in PNG. In this Chinese study, the authors showed that the oblique illumination with flashlight and the measure of depth in the peripheral anterior chamber of these eyes provided lower cost per QALY gained among the strategies studied for prevention and detection of this type of glaucoma. There is no evidence in the literature that the cost effectiveness relation of using peripheral iridectomy with laser has been evaluated as a way to prevent the onset and development of primary narrow-angle glaucoma. ${ }^{33}$

\section{Primary Open-Angle Glaucoma (POAG)}

The diagnosis and treatment of POAG are normally held in routine appointments in the ophthalmologist office. American researchers have evaluated if this pattern of conduct would be cost-effective. They found that the diagnosis of POAG in the routine consultation followed by the clinical treatment generated an ICER between US $\$ 46,000$ and US\$28,000 per QALY, therefore being cost-effective to American standards. ${ }^{34}$

Another object of economic evaluation studies in the treatment of POAG is the treatment strategy. What type of treatment is more cost-effective (clinical, laser or surgery)? What is the most cost-effective medication? These are some examples of questions made by researchers in Brazil and in the world.

Noeker and Walt evaluated the cost-effectiveness of glaucoma treatment with monotherapy using one of the three prostaglandin analogues (bimatoprost, latanoprost and travoprost). In this study, they found that the bimatoprost would present the best cost-effectiveness, concluding that in addition to the traditional evaluations of safety and efficacy of medicines, the cost-effectiveness analysis should be considered to assist in individual and collective decision-making. ${ }^{35}$ Other authors found similar results ${ }^{36-37}$ In Brazil, bimatoprost was also the most costeffective in treatment as an isolated drug or in association with the timolol. ${ }^{37-38}$

Yu et al compared trabeculectomy as the initial treatment versus the traditional treatment approach, starting with medications and developing for surgery as needed. In a 4-year period, the initial therapy with trabeculectomy was more costeffective for patients with moderate to advanced glaucoma. ${ }^{39}$

In Australia, the economic impact of glaucoma was evaluated with an economic model. In this study, the authors 
found that the sequence of laser trabeculoplasty followed by a treatment with clinical eyedrops and surgery, when required, would be more cost-effective than any other treatment sequence. In this study, the measure of effectiveness was made in DALYs. ${ }^{40-41}$

Stein et al. used the Markov modeling to demonstrate that in the U.S. both the initial treatment with laser and the initial treatment with prostaglandins were cost-effective. These authors found that in a 25 -year period the ICUR was US $\$ 16,824 /$ QALY for laser and US\$14,179/QALY for the clinical treatment. $^{42}$

In Brazil, the deep non-penetrating esclerectomia was more cost-effective than the prostaglandin analogues alone or in combination with other medications in a 5-year period of follow-up. ${ }^{43}$ In another study, the surgery of glaucoma (deep non-penetrating esclerectomia) was compared to clinical treatment ( 3 medications per patient) in a period of 5 years. The results of this study showed that the clinical treatment alternatives were dominated by the surgery, being SUS (Brazilian Single Health System) the perspective of costs. ${ }^{44}$ The methodologies in these two studies have important limitations preventing or hindering a generalization and practical applicability of their results for the Brazilian population. The effectiveness of interventions was measured in percentage of reduction of the PIO, and not in QALYs. The authors considered a relatively short horizon (5 years) for a chronic illness, and used decision trees rather than the more suitable Markov model. In addition, funding costs were incomplete (consultations, examinations, etc. were excluded).

There is also a shortage of quality scientific evidence of cost-effectiveness and cost-utility for the treatment of glaucoma within the Single Health System (SUS). Such evidence could facilitate decision-making and help establish practice guidelines and clinical conducts the for Reference Centers for the Treatment of Glaucoma from SUS.

\section{Conclusion}

The analysis of cost-effectiveness and cost-utility is a study of great value in today's world, where there is a shortage of health resources associated to the increased availability and costs of technologies and interventions in health. When including both the costs and the consequences of the alternatives studied in the analysis, the results provide a parameterized reference to assist the health decisionmaking.

The methodology employed is usually based on mathematical models that are fed by the best scientific evidence available about the subject.

There is already enough evidence of cost-effectiveness and cost-utility in the field of glaucoma. However, in Brazil, evidence is still weak, and the studies are incipient. Further studies with rigorous methodology are required to improve the efficiency of the diagnosis and the treatment of glaucoma.

\section{ACKNOWLEDGEMENTS}

The authors have received funding for part of the research from Fundação de Amparo à Pesquisa do Estado de Minas Gerais (FAPEMIG).

\section{ReFERENCES}

1. Frick KD, Kymes SM. The calculation and use of economic burden data. Br J Ophthalmol. 2006; 90(3): 255-7.

2. Taylor HR, Pezzullo ML, Keefee JE. The economic impact and cost of visual impairment in Australia. Br J Ophthalmol. 2006; 90(3): 272-5.

3. Frick KD, Foster A. The magnitude and cost of global blindness: an increasing problem that can be alleviated. Am J Ophthalmol. 2003; 135(4): 471-6.

4. Frick KD, Gower EW, Kempen JH, Wolff JL. Economic impact of visual impairment and blindness in the United States. Arch Ophthalmol. 2007; 125(4): 544-50.

5. Quigley HA, Broman A. The number of people with glaucoma worldwide in 2010 and 2020. Br J Ophthalmol. 2006; 90(3): 262-7.

6. Resnikoff S, Pascolini D, Etya'ale D, Kocur I, Pararajasegaram R, Pokharel GP, Mariotti SP. Global data on visual impairment in the year 2002. Bull World Health Organ. 2004; 82(11): 844-51.

7. Schmier JK, Halpern MT, Jones ML. The economic implications of glaucoma: a literature review. Pharmacoeconomics. 2007; 25(4): 287-308.

8. Doshi A, Singh K. Cost-effective evaluation of the glaucoma suspect. Curr Opin Ophthalmol. 2007; 18(2):97-103.

9. Vianna CM, Caetano R. Avaliação tecnológica em saúde: introdução a conceitos básicos. Rio de Janeiro: UERJ; 2001.

10. Simoens S. Health economic assessment: a methodological primer. Int J Environ Res Public Health. 2009; 6(12): 2950-66.

11. Rascati KL. Introdução a farmacoeconomia. Porto Alegre: ArtMed; 2010.

12. Muennig P. Cost-effectiveness analysis in health. A practical approach. 2a ed. São Francisco: Jossey-Bass; 2008.

13. Brown MM. Health care economic analysis. Curr Opin Ophthalmol. 2003; 14(3): 117-21.

14. World Health Organization. Threshold values for intervention cost-effectiveness by region. Cost-effectiveness and strategic planning (WHO-CHOICE) [Internet]. [cited 2015 Aug 21]. Available from: http://www.who.int/choice/costs/CER_levels/en/.

15. Brown GC, Brown MM, Sharma S, Brown H, Smithen L, Leeser DB, et al. Value-based medicine and ophthalmology: an appraisal of cost-utility analysis. Trans Am Ophthalmol Soc. 2004; 102: 17785. discussion 185-8.

16. Diretrizes metodológicas: Diretriz de avaliação econômica. 2a ed. Brasília(DF): Ministério da Saúde; 2014.

17. Rodriguez Barrios JM, Serrano D, Monleón T, Caro J. Los modelos de simulación de eventos discretos en la evaluación económica de tecnologías y productos sanitarios. Gac Sanit. 2008; 22(2): 151-61.

18. Brown GC, Brown MM, Sharma S, Beauchamp G, Hollands H. The reproducibility of ophthalmic utility values. Trans Am Ophthalmol Soc. 2001; 99: 199-204.

19. Brown MM, Luo B, Brown HC, Brown GC. Comparative effectiveness: its role in the healthcare system. Curr Opin Ophthalmol. 2009; 20(3): 188-94.

20. Brown M. Utility analysis tells all. Br J Ophthalmol. 2005; 89(10): 1233.

21. Brown MM, Brown GC, Sharma S, Kistler J, Brown H. Utility values associated with blindness in an adult population. Br J Ophthalmol. 2001; 85(3):327-31.

22. Paletta Guedes RA, Paletta Guedes VM, Freitas SM, Chaoubah A. Utility values for glaucoma in Brazil and their correlation with visual function. Clin Ophthalmol. 2014; 8: 529-35.

23. Brown MM, Brown GC, Sharma S, Hollands H, Landy J. Quality of life and systemic comorbidities in patiens with ophthalmic diseases. Br J Ophthalmol. 2002; 86(1): 8-11. 
24. Sharma S, Brown GC, Brown MM, Shah GK, Snow K, Brown H, et al. Converting visual acuity to utilities. Can J Ophthalmol. 2000; 35(5): 267-72.

25. Sharma S, Brown GC, Brown MM, Hollands H, Robins R, Shah GK. Validity of the time trade-off and standard gamble methods of utility assessment in retinal patients. Br J Ophthalmol. 2002. 86(5): 493-6.

26. Saw SM, Gazzard G, Au Eong KG, Oen F, Seah S. Utility values in Singapore Chinese adults with primary open-angle and primary angle-closure glaucoma. J Glaucoma. 2005; 14(6): 455-62.

27. Gupta V, Srinivasan G, Mei SS, Gazzard G, Sihota R, Kapoor KS. Utility values among glaucoma patients: an impact on the quality of life. Br J Ophthalmol. 2005; 89(10): 1241-44.

28. Paletta Guedes RA, Paletta Guedes VM, Freitas SM, Chaoubah A. Does the type of treatment have an influence on utility values in a glaucoma population? Clin Ophthalmol. 2015; 9:1645-50.

29. Burr J, Mowatt G, Hernandez R, Siddiqui MA, Cook J, Lourenço $\mathrm{T}$, et al. The clinical effectiveness and cost-effectiveness of screening for open-angle glaucoma: a systematic review and economic evaluation. Health Technol Assess. 2007; 11(41): iii-iv,ix-x,1-190.

30. Medeiros FA, Weinreb RN, Sample PA, Gomi CF, Bowd C, Crowston JG, et al. Validation of a predictive model to estimate the risk of conversion from ocular hypertension to glaucoma. Arch Ophthalmol. 2005; 123(10): 1351-60.

31. Kymes SM, Kass MA, Anderson DR, Miller JP, Gordon MO. Management of ocular hypertension: a cost-effective approach from the Ocular Hypertension Treatment Study. Am J Ophthalmol. 2006; 141(6): 997-1008.

32. Stewart WC, Stewart JA, Nasser QJ, Mychaskiw MA. Cost-effectiveness of treating ocular hypertension. Ophthalmology. 2008; 115(1): 94-8.

33. Yu Q, Li S, Ye T. Cost-effetiveness analysis of the screening strategies for primary angle closure glaucoma. Yan Ke Xue Bao. 1997; 13(4): 202-9.

34. Rein DB, Wittenborn JS, Lee PP, Wirth KE, Sorensen SW, Hoerger TJ, et al. The cost-effectiveness of routine office-based identification and subsequent medical treatment of primary open-angle glaucoma in the United Stated. Ophthalmology. 2009; 116(5): 823-32

35. Noecker RJ, Walt JG. Cost-effectiveness of monotherapy treatment of glaucoma and ocular hypertension with the lipid class of medications. Am J Ophthalmol. 2006; 141(Suppl 1): S15-S21.
36. Frenkel RE, Frenkel M, Toler A. Pharmacoeconomic analysis of prostaglandin and prostamide therapy for patients with glaucoma or ocular hypertension. BMC Ophthalmol. 2007. 7:16.

37. Guedes RA, Guedes VM, Chaoubah A. Custo-efetividade dos análogos de prostaglandinas no Brasil. Rev Bras Oftalmol. 2008; 67(6): 281-6.

38. Guedes RA, Guedes VM, Borges JL, Chaoubah A. Avaliação econômica das associações fixas de prostaglandina/prostamida e timolol no tratamento do glaucoma e da hipertensão ocular. Rev Bras Oftalmol. 2010; 69(4): 236-40.

39. Yu E, Hay J, Varma R, Globe D. Four-year cost-effectiveness of inital trabeculectomy versus conventional therapy in primary open angle glaucoma. Value Health. 2008; 44(2): 119.

40. Centre for Eye Research Australia. Tunnel Vision: the economic impact of primary open angle glaucoma - a dynamic economic model. Australia: University of Melbourne; 2008. 105 p.

41. Dirani M, Crowston JG, Taylor PS, Moore PT, Rogers S, Pezzullo $\mathrm{ML}$, et al. Economic impact of primary open angle glaucoma in Australia. Clin Experiment Ophthalmol. 2011; 39(7): 623-32.

42. Stein JD, Kim DD, Peck WW, Giannetti SM, Hutton DW. Costeffectiveness of medications compared with laser trabeculoplasty in patients with newly diagnosed open-angle glaucoma. Arch Opththamol. 2012; 130(4): 497-505

43. Guedes RA. A esclerectomia profunda não penetrante como forma da prevenção da cegueira pelo glaucoma e seu impacto na saúde coletiva. Um estudo de custo-efetividade [dissertação]. Juiz de Fora: Universidade Federal de Juiz de Fora; 2008.

44. Guedes RA, Guedes VM, Chaoubah A. Cost-effectiveness comparison between non-penetrating deep sclerectomy and maximum-tolerated medical therapy for glaucoma within the Brazilian National Health System (SUS). Arq Bras Oftalmol. 2012; 75(1): 11-5.

\section{Corresponding author:}

Ricardo Augusto Paletta Guedes.

Av Barão do Rio Branco, 2644 apt 1001, Centro. Juiz de Fora MG. ZIP Code: 36016-311.

Phone: 3232152733.

E-mail: palettaguedes@yahoo.com. 